\title{
The "Ecosystem" of Education, Engagement, and Environmental Action in Higher Education
}

\author{
Isabelle Seckler
}

\begin{abstract}
As a rising sophomore at Columbia University (as of the summer of 2020), my engagement with climate and environmental education spans multiple community settings, each with its challenges. Having committed myself to environmental stewardship and science communication, I am learning how to adapt to different audiences. The most important lesson I've learned is that climate action education must be made personal: students themselves must reach a critical understanding that their lives are inextricably tied to the state of the planet. We can become more powerful as agents of change by providing students with sustainable development as a framework, so that they may, through experiential learning, integrate climate issues with their respective academic interests. For the sake of increasing resiliency, quality undergraduate education must be reoriented to incorporate climate literacy and systems thinking across all academic disciplines. The radical simplicity and effectiveness of this approach further supports the growth of "translational" competencies; that is, the approach empowers and catalyzes students to move radical change beyond the classroom, even as they transition to virtual schooling. My self-driven approach to learning has opened many doors for translating education into action beyond the classroom. In this essay, I highlight the key points in my journey so far with sustainable development education.
\end{abstract}

\section{Keywords}

education for sustainable development - communication - higher education - interdisciplinary - systems thinking - biomimicry

I believe that effective communication is the most important aspect of environmental action for the generation of climate solutions. That is why I spent

(C) UNESCO IBE, 2021 | DOI: 10.1163/9789004471818_015

This is an open access chapter distributed under the terms of the CC BY 4.0 License.

Isabelle Seckler - 9789004471818 
most weekends in high school chopping up squid to feed puffer fish, stingrays, sea turtles, and eels - and smelling like squid. It was a small price to pay for my local nature center's allowing me to volunteer to give the daily feeding presentation about south Florida's coastal ecosystem. Using this platform, I spoke to crowds of around 250 people about the connections between society and the marine environment.

As I gained a new perspective on the ecosystem that I call my backyard, I discovered how to help others do the same. At Gumbo Limbo Nature Center, not only did I find my voice, but I also learned that education for environmental action can come from helping people identify themselves as part of the greater ecosystem of life.

I applied to Columbia University (boldly stating, "I smell like squid") because of its dedication to investigating the links between climate and society. Now, in the summer of 2020, a rising sophomore who finished my first year at Columbia amidst a global pandemic, I can reflect on what continues to mobilize my passion for a quality education in sustainable development.

\section{Action for One's Own Well-Being}

There is no better way to create a culture of sustainability than to empower students to take action for the sake of their own well-being. Although I grew up watching algal blooms poison Florida waterways, hurricanes destroy neighborhoods, mangrove habitats disappear, and rising sea levels threaten cities, most students are unaware of the impact of climate change on their communities. Effective climate education must demonstrate how the effects of change are personal. A quality sustainability education should prompt students to consider their local natural and built environments. Because not every student has a connection with nature like mine, I see that it is critical that schools integrate climate science into each curriculum, and even more important, help students recognize why this body of knowledge is directly relevant to them. This communication will encourage students to engage with solutions for a more resilient world.

\section{The Evolution of a Childhood Adoration}

A childhood fascination with my local environment evolved into a persistent desire to understand socio-ecological relations. While I am fortunate to have 
access to a quality education, I have always felt a personal responsibility for, and exercised agency over, acquiring knowledge.

My informal, curiosity-driven interests have helped me explore multifaceted issues in formal settings, as well. For my first-year writing seminar, I wrote a research paper on how the exploitation of land and labor for cotton production in Central Asia decimated the Aral Sea. For a mock science-policy brief, I researched the health implications of harmful algal blooms caused by nutrient pollution in south Florida. In high school I even wrote a research paper on the overharvesting of horseshoe crab blood, which is used in vaccinations. My motivation in taking on all these projects was my interest in human health and medicine. These projects were related tangentially, at most, to the courses I was taking, but I took the opportunity each time to fully dive into an unknown topic. I am proud that I have used projects, essays, research reports, and so on, to explore interdisciplinary linkages, going so far beyond the standard introlevel lectures that most first-year students enroll in. Because this approach has added considerable originality and interest to my school experience, I have pushed hard in my essays and school assignments to draw connections between medicine, economics, and the environment. I hope that instructors realize that all students learn best when they are passionate about the subject matter and that they can let students' curiosity lead them beyond the confines of the classroom.

Students should be encouraged to investigate on their own, to read articles, follow accounts on scientific social media, and explore the little secrets of life that science lets you in on. I find the inspiration to explore topics I had neither the chance nor the time to study in school. Randomly one night I put on the Netflix show Abstract: The Art of Design, which highlights Massachusetts Institute of Technology Media Lab designer Neri Oxman. Learning about her work with sustainable bio-architecture brought me to tears. It was the first time I recognized a community that shares my perspective of applying nature's expertise to the very structure of our society. It reassured me that reconnecting with nature offers a new sustainability perspective.

For a writing seminar Op-Ed project, I revisited an interest first sparked in high school - how climate tech could spur a revolution based on nature's evolution. The Earth Institute published my piece. Soon after, the communications director of the Biomimicry Institute reached out to see if I'd be interested in writing for them (this was a few weeks after they had turned me down for a summer internship). Fast forward seven months, and I've written eight articles about increasing efficiency through natural modeling in fire recovery, biomedicine, education as an ecosystem, and more. I have connected both 
professionals and undergraduate students with interesting science they would otherwise have had little understanding of.

I first learned about bio-inspired design from a YouTube video, and I remember telling my Advanced Placement biology teacher about how astonishing it was. Then I happened upon a book explaining the science of turning animal toxins into treatments for diseases, including Duchenne Muscular Dystrophy, which my cousin suffers from. A few TED talks later, biomedical entrepreneur Dr. Jeffery Karp became my hero for his radically simple approach to biomimicry in medicine. Now I have interviewed CEOs and expert scientists from around the world on their work, including Dr. Karp. This experience shows how proactive learning can lead to advanced opportunities.

It does not take an Ivy League (or any other prestigious) institution such as Columbia University to empower youth to build a community in favor of climate or environmental action. It simply requires an individual's curiosity, passion, and urgency for change. But institutions of higher education can support interdisciplinary thinking and experiential learning. Especially during the virtual distance-learning of the Covid-19 era, it will be up to students themselves to pursue a meaningful and practical education relevant to today's challenges. Students themselves must learn how to engage in conversations with others in order to learn with benefit of others' experience.

Climate action requires a multidisciplinary understanding of the socio-economic, geopolitical, and environmental contexts of local impacts. I need my educational background to align with the range of fields through which I plan to engage with climate issues. My approach fills in, and supplements, existing sustainability education; in the existing structure, I am struggling to coordinate the knowledge and experiences I see necessary for such action in just one major, minor, or area of study. The transformative change necessary for a climate-relevant university education is the creation of interdisciplinary linkages. Even within the existing academic curriculum, each respective subject should enable students to better question and comprehend the environmental considerations, factors, and implications of that field. We should be learning through case studies of social impact, grassroots movements, and historical moments of change, all of which can help students navigate the reality of a complex world through a perspective of systems thinking.

The paradox in my academic curiosity about STEM topics and policy is rooted fundamentally in the challenge of achieving the UN Sustainable Development 
Goals (SDGs): you cannot create good health and well-being for all without climate action; you cannot have zero poverty without clean water and sanitation; and you cannot create sustainable societies without strong institutions for peace. The intersecting linkages of the SDGs represent the broad goals of creating a brighter future. Understanding quality health care and medicine, on a larger scale, requires that I am fully equipped to understand the ecological and geopolitical contexts of community health. The pandemic demonstrated just how grounded this requirement is in the reality of a global society. Universities should develop curriculums to help students discuss real case studies with equally multifaceted perspectives.

\section{$5 \quad$ Developing a Culture for Sustainability Education}

Sustainability education raises questions. For students to learn of the widespread challenges and systemic injustices that plague communities around the world is overwhelming if they cannot see a sustainable solution for them. Where does a student begin to tackle these challenges? How can a student develop a generalized framework for understanding these challenges, and also acquire specialized expertise useful in addressing them?

The entry points for climate action are many and include the range of all possible perspectives in academia. Universities can help students chart their own pathways with regard to climate action by introducing relevant climate-related issues into each respective field. A university can, for example, set up a dialogue for engineers on green design, prompt anthropologists to investigate urban air pollution, and teach economists about environmental externalities; a university can facilitate interdisciplinary conversation and collaboration.

Only so much time can be spent in one classroom, but lives are not shaped by a subject learned in isolation. The parallels that can be drawn among individual classes interests me much more. This quest for interconnecting subjects is also why students like me join special-interest clubs and organizations like, for example, the Alexander Hamilton Society that I joined. It's a non-profit, non-partisan organization dedicated to educating about, and launching students into, foreign policy and national security issues. I approach this organization from the perspective of wanting to promote eco-literacy, and sustainable peace between international actors and the environment. As a chapter officer for the next year, my hope is to facilitate discussions on the way climate change acts as a catalyst for, or exacerbates, conflict, strife, and security concerns.

The Upper West Side of Manhattan, where I live when I am at school, presented a stark contrast to the environment I grew up in. But in New York the 
effects of climate change were just as visible as they were back home. Rising temperatures, a winter without snow, and disproportionately situated pockets of air pollution were clear signs of damage. But my peers don't necessarily see them.

Usually, college students unfortunately mislabel climate solutions as "environment activism", which connotes a concern limited only to environmental studies. This misunderstanding is what drives me to find effective ways to communicate to my classmates that sustainability is not just veganism and giving up plastic straws: sustainable development connects to every department, every subject, and every aspect of life.

In February of 2020, I joined the UN Sustainable Development Solutions Network (SDSN) Youth, as a volunteer project officer for its SDG Students Program. United Nations Secretary-General Ban Ki-Moon launched SDSN in 2012, with SDSN Youth following in 2015, to mobilize global expertise around the SDGs. The SDG Students Program is a semi-virtual, semi-physical community of university hubs that integrates sustainable development into higher education. The intent of this program is to enable the next generation of university graduates to be sustainability-minded professionals.

Seventy university hubs around the world range from Kenya to Canada, and the 14-person administrative team I work with represents at least 13 countries. I have connected with leaders in conservation, policymaking, and international climate policy. My work on the team has helped me visualize the best pathways for encouraging others in sustainability literacy. But the most important lessons I have learned come from the students who lead their campus hubs. Around the world, a community of innovative college students is transforming the very role of education to make it fit the context of today's world. Each campus hub serves as a point of unity and collaboration for local action, as well as building capacity to address concrete issues. Students have led beach cleanups and recycling campaigns, and they have championed university policy change. All these actions are driven by students' passion to create a better community. This upcoming school year, I will build a Columbia SDSN Youth Hub and partner with Columbia's Office of Environmental Stewardship to foster a culture of sustainability on campus.

In the spirit of SDG 17 (on global collaboration), I started an initiative for conversation-centered creativity using OneHub, a virtual meeting space. My initiative is designed to foster camaraderie among our campus leaders. Especially 
at a time of social distancing and perils to well-being, this initiative helps to engage people in action and in forming genuine friendships through cultural exchange. I find it inspiring to work with the exceptional students involved in the initiative as I chart my own pathway to integrating sustainability into Columbia's student culture and now, into higher education on a global scale. Communication proves key in sharing knowledge and perspectives to grow a program from the ground up.

Passion leads to proactiveness, which has been a crucial factor in my trajectory. I am constantly learning about different aspects of sustainability, not only gaining substantive knowledge, but also navigating the virtual workplace, developing expertise in teamwork across language differences, amidst a global pandemic. I moderated my first webinar on geopolitical conflict resolution with National Geographic explorer Joshua Powell. A few weeks later, I chaired an event for Dr. Lisa Dale who shared her work on climate change adaptation in Rwanda. This semester, I'll moderate an event with the founder of the Center for Earth Ethics, Karenna Gore. I am able to craft conversations that resonate with our students, because I crave such mentorship and advice myself. What skills should I focus on to be a better leader? What are realistic action steps for getting involved, and how can I adapt them to my local community? Simply by having these conversations, I'm becoming a more confident agent of change.

\section{7}

\section{Conclusion}

Education about climate change is no longer a choice; it is an imperative of living in today's political, social, and environmental reality. The lessons, and therefore the effects, of postponing sustainable development are visible every day for youth everywhere in the world. If education at every level is grounded in the day-to-day reality of environmental, economic, and social issues, youth can effectively create pathways of change. Reconnecting youth with climate and environmental knowledge that is distinctly relevant to their own lives will empower them as agents of their own survival. Higher education, in particular, has the power to embolden its students with the capacity to confidently take ownership of their future. It should begin by reconnecting students to the state of our planet, and how it shapes the state of humanity. The "ecosystem of education" must adapt.

To any student pursuing an interdisciplinary path: remember that you do not need to be an expert in everything if you can collaborate with a diverse group of people. You must, however, be able to communicate across different disciplines - to enhance synergy and social impact. You must learn to view 
problems through different perspectives. That variety, to me, is the reality of life and of sustainable development. By definition, sustainable development requires a community to think through the tough issues together. My generation is facing unprecedented challenges, but we have the tools to innovate, learn, and collaborate with one another. This will be the generation to make an impact unlike any before. Change starts with one local step, even if it means you might smell like squid. 